Available online at www.jmle.org

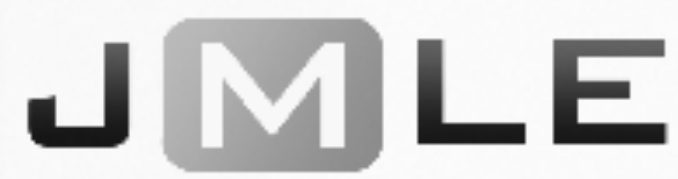

The National Association for Media Literacy Education's

Journal of Media Literacy Education 10 (2), 1 - 10

\title{
Media Literacy, Democracy, and the Challenge of Fake News
}

\author{
Lance E. Mason \\ Indiana University Kokomo \\ Daniel G. Krutka \\ University of North Texas \\ Jeremy Stoddard \\ College of William \& Mary
}

\begin{abstract}
In this essay, the authors offer a context for discussions about fake news, democracy, and considerations for media literacy education. Drawing on media ecology and critical media studies, they highlight the longer history of fake news and how this concept cannot be separated from the media technologies in which cultures grow. They discuss current iterations of this phenomenon alongside the effects of social media and offer a preview of the contents of this special issue on media literacy, democracy, and the challenge of fake news.
\end{abstract}

Keywords: media literacy, fake news, media ecology, social media

Democracies rely on informed citizens. The media forms from which citizens learn about political happenings have shifted and mingled over time from pamphlets and newspapers to radio and television to cable news and social media. Our media environment has never been so complex. While media literacy advocates and educators have sought to organize curriculum which might prepare citizens to be informed for democratic participation (Bulger \& Davison, 2018; Stoddard, 2014, Mason \& Metzger, 2012), many schools have been slow to implement such curriculum. While these issues were not new, the candidacy and presidency of Donald Trump have pushed them into the foreground. He regularly uses Twitter to engage in partisan politics, threaten nuclear war, malign political opponents, dehumanize groups of people, and label mainstream media outlets as fake news. While politicians and citizens carelessly use the term, educators must wrestle with complex issues around not only information literacy, but also young people's understanding of the wider effects of media forms on their knowledge and beliefs.

Our aim in this introduction is to consider the concept of fake news for media literacy and democracy more broadly, while offering a framing and context for the 
research articles and essays in this special issue. In recent times, the term fake news has been used to describe fictitious articles that spread easily among social media sites like Facebook. In his first presidential press conference, Donald Trump arguably weaponized the term by declaring media outlets like CNN as fake news. As editors of the special issue, we want to take this opportunity to explore both the reasons for its ascent and how it contributes to understanding the changing media landscape that has been deeply influenced by new media technologies, and consider what this means for educators seeking to address media literacy in light of the challenges presented by fake news.

In this introduction, we will consider fake news from perspectives not always included in the current debate for how to respond as educators, which includes strategies for identifying fake news (e.g., news literacy) and analyzing information media as texts (e.g., media literacy). We go beyond these models by utilizing more critical perspectives and through examining media engagement from the conceptual grounding of media ecology. Media ecologists study media as environments that structure human interaction. Neil Postman (2000) explains:

A medium is a technology within which a culture grows; that is to say, it gives form to a culture's politics, social organization, and habitual ways of thinking. Beginning with that idea, we invoked still another biological metaphor, that of ecology....We put the word "media" in front of the word "ecology" to suggest that we were not simply interested in media, but in the ways in which the interaction between media and human beings gives a culture its character and, one might say, helps a culture to maintain symbolic balance. (pp. 10-11)

Media ecologists study how media forms influence personal actions, interpersonal engagement, and broader societal changes. This places an emphasis on considering how new media technologies create new possibilities for social and political engagement, while affecting existing media dynamics in both positive and negative ways. Our analysis will also employ Herman and Chomsky's (1998/2002) critical analysis of media, which identifies the power interests involved in locating, crafting, and disseminating media messages as a key factor in understanding why certain ideas and messages are given heavy attention by the media, while others are ignored. Together, these perspectives provide the grounding for understanding the rise of fake news as a concept and how it limits or promotes understanding of the changing dynamics between media and democracy, while also considering how media literacy education might respond to these changes.

In the Cambridge English Dictionary (n. d.), fake news is defined as "false stories that appear to be news, spread on the Internet or using other media, usually created to influence political views or as a joke." However, media scholar Brian McNair (2018) offers another definition: "Intentional disinformation (invention or falsification of known facts) for political and/or commercial purposes, presented as real news" (p. 38). Both definitions identify intention as part of what distinguishes fake news from other longstanding media concerns such as journalistic or editorial errors. These two definitions usefully encapsulate the concept, though the growing concern with the power to influence ideas through mediated communication can be more robustly understood by putting the term in its historical context and subsequently exploring the changing media landscape. Further, the term fake news has been used effectively by President Trump and other 
members of his administration to attempt to delegitimize journalists and any journalism outlet that publishes stories they disagree with or that are critical of them. This use of the term has potential long term effects on how the public view or trust journalists and news outlets and is historically grounded in authoritarian regimes that want direct lines of communication to the public and their supporters in particular (Levi, 2017).

\section{A BRIEF HISTORY OF MEDIA MANIPULATION}

The term fake news is far from a new idea. It appears to have emerged in the late $19^{\text {th }}$ century, although similar terms such as false news have been around since the $16^{\text {th }}$ century (Merriam-Webster, n.d.), and the ability for news to distort public opinion for political or pecuniary ends has long been understood. In the late $19^{\text {th }}$ century, yellow journalism was a term used to describe exaggerated or outright fabricated stories and like today's fake news - was connected to profit motives by news organizations. Yellow journalism has been blamed for stoking the fervor that led to the Spanish-American War and was arguably the forerunner of what became tabloid journalism. While concerns with yellow journalism faded during the progressive era, concerns of media manipulation arguably reached an apex in the 1920s with the publication of Walter Lippmann's (1922) Public Opinion. Lippmann, drawing on his experiences writing for the War Department and the State Department during World War I, was shaken at how easily the public had been manipulated into supporting a war it initially opposed. Since that time, scholars and public intellectuals have chronicled the power of media to mold mass opinion in support of various political agendas.

New mass media technologies have always presented novel opportunities for those in positions of power to influence citizens. Hitler used the intimate, one-way communication of the radio to rally German citizens behind his nationalistic, imperial agenda. Similarly, Franklin D. Roosevelt hosted radio-based "fireside chats" to convince Depression-weary American citizens to support New Deal reforms. Radio also provided a new avenue for advertisers, who leveraged the new technology to reach massive audiences simultaneously, which helped to increase the role of consumerism in American culture.

The proliferation of the television introduced new possibilities for persuasion that were capitalized on by both advertisers and politicians. Businesses were now able to add moving visuals to their sales pitches. Over time, politicians began to take advantage of the multi-sensory features of television to create favorable sense-impressions while minimizing substantive policy stances that might offend potential voters. Meanwhile, the mass nature of television news limited perspectives and variety. It also facilitated what Daniel Boorstin (1961) called pseudo-events such as press conferences, photo opportunities, and other staged events that are planned specifically to be covered by the press.

Although media manipulation is an old story, the term fake news has not been a key term in media discourse until recently. Concerns about this concept can be understood within the context of the emergence of new technologies intersecting with current sociopolitical and economic dynamics. For decades in the U.S. and Europe, promoters of neoliberal corporate capitalism have rejected any notion of the public or common good, which led to lax enforcement of the public interest doctrine for mass media established by the Communications Act of 1934. This doctrine was ultimately abandoned in the mid 
1980s. With the lack of regulatory enforcement, media companies began operating under an overt profit motive. Cable news and talk radio began to segment news audiences into ideological camps. An emphasis on profits has decimated local news coverage, while leading to such things as canned news, or pre-packaged news segments designed for mass dissemination among local affiliate new stations. This also presented new opportunities for political manipulation. In one documented example, the Bush administration produced canned news stories promoting several of their policy goals, including supporting the invasion of Iraq (see Barstow \& Stein, 2005). Such stories were designed to appear as objective news coverage and were shown on local news stations as regular segments, but they were designed by Bush administration officials with the aim of bolstering specific policy positions. Similarly, the Sinclair Broadcast Group requires local news stations across the country to air right-leaning "must run" segments, including "Terrorism Alert Desk" stories that serve to stoke fear and serve political aims (Ember, 2017). The Trump Administration has also produced short videos where he describes a current initiative, meeting, or policy made to look like he is being interviewed - with the goal of promoting his agenda. These videos are released by the White House and then often shared with or without comment on cable news and through social media - an example of what is referred to as free media coverage or earned media.

\section{NEW MEDIA AND THE RISE OF FAKE NEWS}

The emergence of the Internet and social media have dramatically altered media coverage and perception, and understanding contemporary concerns about fake news require considering the novel social dynamics introduced by new media technologies. In 2017, two-thirds of Americans reported receiving at least some of their news via social media and this percentage rises to three-fourths on the platform where President Trump often posts: Twitter (Shearer and Gottfried, 2017). Social media has been taken up for various political purposes. Platforms have been effectively utilized by marginalized groups seeking freedom or justice; perniciously by totalitarian groups aiming to censor, misinform, or distract; and for different purposes by citizens connecting with fellow activists or disconnecting from those with different views (Tufekci, 2017). Moreover, these new media technologies both increase the volume of news while allowing niche marketing on an unprecedented scale, often presenting ideologically bifurcated readers and viewers with entirely different universes of discourse, which has fueled political polarization.

While social media companies capture public attention, newspapers have experienced shrinking add revenue due to pressures from diminished sales because of competition from the Internet. Many agencies have either closed or contracted, which has led to diminished local news coverage and less in-depth reporting. It has also increased the likelihood of reporting factual errors or passing along public relations material as news without thoroughly vetting it for bias or inaccuracies. Newspapers increasingly depend on Internet ad revenue, leading to heightened pressure for headlines or stories that are hyperbolic or sensationalistic. Such stories are more likely to go viral, generate clicks, and thus contribute to the company's bottom line.

Media dynamics surrounding the emergence of the Internet and social media have also heightened the impact of media manipulation. For example, in his book Trust Me, I'm 
Lying: Confessions of a Media Manipulator, Ryan Holiday (2012) explains how he exploits the new media environment to create buzz around products for his various clients. In a process he calls trading up the chain, Holiday explains how he plants a story with a small blog with low reporting standards, which becomes the source for a larger, more reputable blog, which subsequently may get picked up for coverage by mainstream outlets. One may question why major news organizations would cover unverified information from a blog. Holiday explains that news outlets, in their desperation for readers and clicks, are now more likely to practice what he calls "iterative journalism" (p. 167), which is repeating unverified stories from less reputable sources under the pretense that the story is still in process and the facts are incomplete. Yet this is part of the manipulation. Reporters often know the stories are bogus so they rarely investigate further and instead content themselves with the temporary increase in clicks. Moreover, media aggregators seeking attention will pull quotes from informal conversations on audio podcasts or radio shows and then highlight and frame these quotes as news with neither the context of the conversation nor consideration of the difference between conversation and written forms.

Moreover, astroturfing is a phenomenon in which entire grassroots groups are manufactured in order to give the pretense of popular support for an issue or cause. Common activities include creating commercials or hiring actors to protest either for or against some organization or legislation, the latter intended to garner news coverage, YouTube clicks, and shares through social media. These techniques among others leverage the potential of social media users to spread stories and generate buzz, while heightening the public's suspicion of news coverage in general. Beyond commercial ambitions, authoritarian leaders have utilized these same strategies to mislead, confuse, or exhaust citizens from engaging with social issues (Tufekci, 2017).

McNair (2018) asserts that fake news "is a discourse about journalistic bias as much as it is about the fabrication of facts; an attempt to subvert the legitimacy of an information source who claims to be 'objective' but is, in the eye of the accuser, biased against their side of a particular issue" (p. 25). Media factions now expend a great deal of energy pointing out the bias and factual errors of the other side. This performs a useful watchdog function, although in an already segmented media environment, it also contributes to political polarization while eroding public trust in the media, which according to Gallup (2016), has been steadily falling for the past 40 years. Corrections or refutations are also now less likely to penetrate deeply into public consciousness partly because of ideological segmentation (meaning that those who would most likely be enlightened by the information are least likely to receive it), but also because of the volume of information now available to consumers, which tends to overwhelm any sense of coherency that would connect one story to subsequent ones. Self-selection of media sources and motivated reasoning, or the selection of evidence from news to support existing beliefs and rejecting information that may counter one's beliefs further exacerbates the issue of fake news (Kahne \& Bowyer, 2017). The irony is that within the relatively open media environment of the Internet, media distortions and lies are often exposed by alternative media and other groups, yet this only adds to the public perception that we live in a "post-truth" era dominated by fake news.

Mainstream news organizations also suffered a major blow to credibility during the U.S. presidential election of 2016 when Wikileaks revealed that many reporters from 
mainstream news agencies were working with the Clinton campaign to ensure her victory over Democrat primary opponent Bernie Sanders. News coverage of the contest often contained only the slightest pretense of neutrality. In one example of slanted coverage, a review of approximately 200 editorials and op-eds in the Washington Post from January to June 2016 found 5 negative stories for every positive one on Sanders. By comparison, stories on Clinton were split about half positive, half negative (see Frank, 2018).

Wikileaks also revealed that the Clinton campaign was working with their allies in the media to bolster what they perceived as the most vulnerable Republican candidates: Ben Carson, Ted Cruz, and Donald Trump (Debenedetti, 2016). When Trump won the Republican nomination for president, the press quickly turned on him and showed blatant favoritism for Clinton. This may have created a backlash from some voters, though it certainly provided the rhetorical space for Trump to take an oppositional stance to the media and label them as fake news, at least in a way that was convincing to his staunchest supporters, who were already disgruntled with the media coverage of Trump during the election season. This is not meant to provide a justification for Trump's attacks on the media. Rather, it is to assert that understanding our current media environment requires considering how mainstream media has lost credibility with many citizens for reasons that must be confronted if media is to serve its ideal role as informer of citizens and watchdog of the powerful.

Within these media and social contexts, the increased reliance and role of citizens to encounter and spread news through social media presents new challenges for democracy and media literacy. Social media companies like Facebook are designed to induce habit-forming use with notifications and algorithms that offer decontextualized fragments of information (similar to the telegraph) that make knowing of things more important than knowing deeply about them (Vaidhyanathan, 2018). Furthermore, Siva Vaidhyanathan (2018) describes a cryptopticon whereby these companies serveil citizens through the collection of massive amounts of data which is then sold off, stolen, or used for marketing purposes to profile individuals in unprecedented ways. Users tend to accept this invisible surveillance for convenience, efficiency, or security without considering threats to privacy and democracy. As we have discussed, social media has allowed for marginalized voices to raise the profile of social issues (e.g., \#BlackLivesMatter, \#MeToo, \#TimesUp) or even organize activist activities on the ground (e.g., \#TahrirNeeds, @TahrirSupplies). Yet, social media platforms pose significant challenges as our spaces for news consumption and public discourse are increasingly controlled by private corporations who desire markets over democracy.

\section{FAILING MEDIA, FALTERING DEMOCRACY, AND MEDIA LITERACY}

Public trust in media has declined roughly in step with a distrust of politicians and a general diminishing faith in public institutions throughout the neoliberal era. However, these events should also be understood within the context of falling incomes and decreased future prospects for large portions of the U.S. population. The decline in trust of media is connected to the broader waning support for public institutions, all of which rests of the experiences of citizens whose lives have become more difficult over the preceding period even as media tells them that the economy is doing well and that the nation is 
prospering. In distressing times, ideological appeals tend to hold greater sway over the population, particularly when news coverage does not line up with their lived experiences.

The above challenges to liberal democracy presented by new media dynamics has resulted in calls for rethinking the role of media literacy (Mason \& Metzger, 2012; Mihailidis, 2018; Stoddard, 2014), educational social media activities (Krutka, 2017), and civic online reasoning (McGrew, Breakstone, Ortega, Smith, \& Wineburg, 2018) in education. Media literacy can be broadly defined as the "active inquiry and critical thinking about the messages we receive and create," (National Association for Media Literacy Education, 2007) and media literacy efforts have resulted in both successes and failures (Bulger \& Davison, 2018). As we do here, Bulger and Davison argue that effective media literacy education requires understanding the media environment in addition to improving cross-disciplinary collaboration; leveraging the current crisis to consolidate stakeholders; prioritizing approaches and programs with evidence of success; and develop action-oriented curricula that challenges systemic problems created by media, including social media; corporations in addition to teaching individuals to interpret media messages. Additional questions remain. Should fake news become more of a central focus of media literacy education, or do these challenges suggest that a more fundamental reframing of media education is necessary that puts media literacy at the forefront of $21^{\text {st }}$ century education?

If fake news is simply treated as an add-on to an existing media literacy curriculum, teachers will merely create exercises that will help students determine whether a particular story can be considered fake or not. While this would be useful, it does not begin to address the reasons why the phenomenon of fake news has arisen within the culture in recent years. To examine this, media literacy would need to become a central part of school curriculum. A deep understanding of the history of media in the United States would need to be explored by students. The intricacies of private enterprise and public interests surrounding media would need to become focal questions for student deliberation. Contemporary media dynamics would also need to be examined and such inquiries could begin by having students examine their own media use and how it shapes their worldview. The public and students alike would also need to reflect on their own role in propagating fake news through their own media-seeking habits and through the ways in which they share news within their social networks (see Middaugh's article in this issue).

Some questions for the broader society given the challenges of fake news: Should social media be more tightly regulated? Should the public demand that journalism once again operate in the public interest? How can democracy be sustained and renewed in light of such challenges, and is education even capable of offering an adequate defense for new media environments? What role does media education play within civics and democratic education? These questions and more should arguably become part of the exploration that must be grappled with by both media literacy advocates and their students given the challenges surrounding fake news.

\section{PREVIEW OF THE SPECIAL ISSUE}

While answers to many of these questions will require ongoing inquiry, the authors of the special issue begin to take up several of these matters in the studies that follow. In the essay, "Both Facts and Feelings: Emotion and News Literacy," Susan Currie Sivek 
considers the role of emotional manipulation in fake news within the context of social media. The dynamics of social media, which are organized around retaining the attention of users, have bolstered the influence of fake news. Sivek offers metacognitive strategies that could potentially make students more mindful consumers of news and social media. Ellen Middaugh, in "Civic Media Literacy in a Transmedia World," provides empirical evidence focused on the challenges of promoting these kinds of metacognitive thinking and the role that emotion plays in how young people engage with media as consumers and circulators. She explores how young people engage with information across media through the use of an Issue Advocacy Task and pays particular attention to the social and emotional aspects of these engagements in how students analyze these media and consider their practices in sharing information within participatory networks.

The concern with newly emerging forms of manipulation also fuels the study "Fake or Visual Trickery? Understanding the Quantitative Visual Rhetoric in the News," by Rohit Mehta and Lynette DeAun Guzman, who examine a particular form of visual persuasion in news stories they call "quantitative visual rhetoric." The prevalence of screen news increases the need for media educators to consider how visual aids are used by media organizations in conjunction with text to subtly craft message interpretation. The authors evaluate several key examples and explore their implications for media literacy education. While students' understanding of what they engage with on screen is vital, James Cohen also makes the case for a better understanding of what happens behind the scenes and behind the screens, namely the impact of algorithms on our media engagement and ensuing understandings. In "Exploring Echo-Systems," he makes the case for developing an understanding of the role of algorithms within media ecosystems as a core understanding of media literacy for informed citizenship.

Exploring the consequences for practice is a focus of research by James Damico, Mark Baildon, and Alexandra Panos, whose article titled "Media Literacy and Climate Change in a Post-Truth Society," examines pre-service teachers' interpretations of media arguments regarding climate change. While virtually all climate scientists acknowledge the phenomenon and threat of climate change, there is still a debate among the public about whether climate change is real. This dynamic makes the topic pertinent for considering within the context of fake news. The study examines how pre-service teachers make sense of information that either supports or refutes the existence of climate change, and how media literacy must address both misunderstandings and ingrained ideologies as part of its broader curriculum.

While it is easy to make calls for more media literacy education, implementation within current educational contexts is more challenging. Mardi Schmeichel and her colleagues at the University of Georgia seek to enhance media literacy education for social studies teacher candidates, but found that teacher candidates struggled with these new media literacy concepts of which they had little knowledge or experience. Moreover, the cultures of school proved another barrier as the lack of presence, requirements, or support deterred teacher candidates from engaging in media literacy work for our democracy. A different approach is explored in the work of Renee Hobbs, Christian Seyferth-Zapf, and Silke Grafe titled "Using Virtual Exchange to Advance Media Literacy Competencies through Analysis of Contemporary Propaganda." Their case study of practice describes their collaborative virtual exchange project where teacher education students in Germany 
and media students in the US learned collaboratively about modern propaganda and the challenges it presents for contemporary media literacy education.

Concerns about media literacy and fake news also expand beyond K-12 education into adult contexts. In their evaluation study of the Ukrainian public media education project, Learn to Discern (L2D), Erin Murrock, Joy Amulya, Mehri Druckman, and Tetiana Liubyva found limited effects on the news literacy skills and beliefs in the adults who had participated in the project. They found that available news sources and motivated reasoning seemed to negate some of the news literacy concepts and skills at the heart of the L2D program. These results present further challenges to media literacy educators as they consider how to best craft a curriculum that can help students become discerning consumers and creators of media moving forward.

We hope this special issue inspires educators and scholars alike to take up the challenges that fake news and the associated media environment present for our democratic structures and for participation. While these challenges are not entirely new, they are pressing, complex, and interconnected. We must all consider how media literacy might help prepare citizens for democratic participation within environments that feature increasingly complex and subtle forms of manipulation.

\section{REFERENCES}

Barstow, S. \& Stein, R. (2005). Under Bush, a new age of prepackaged TV news. New York Times, March 13. Retrieved from:

https://www.nytimes.com/2005/03/13/politics/under-bush-a-new-age-ofprepackaged-tv-news.html

Cambridge Dictionary. (n. d.). Fake news. Retrieved on July 2, 2018 from: https://dictionary.cambridge.org/us/dictionary/english/fake-news

Debenedetti, G. (2016). They always wanted Trump. Politico Magazine. Retrieved from: https://www.politico.com/magazine/story/2016/11/hillary-clinton-2016-donaldtrump-214428

Ember, S. (2017, May 12). Sinclair requires TV stations to air segments that tilt to the right. New York Times. Retrieved from https://www.nytimes.com/2017/05/12/business/media/sinclair-broadcast-komoconservative-media.html

Frank, T. (2018). Rendezvous with oblivion: Reports from a sinking society. New York: Metropolitan Books.

Gallup. (2016). Americans trust in mass media sinks to new low. Retrieved on July 3 , 2018 from: https://news.gallup.com/poll/195542/americans-trust-mass-mediasinks-new-low.aspx

Herman, E. S. \& Chomsky, N. (1988/2002). Manufacturing consent: The political economy of the mass media. New York: Pantheon Books.

Hook, J. (September 23, 2018). More voters want democrats to control congress, new poll shows. New York: Wall Street Journal. Accessed online September 24, 2018: https://www.wsj.com/articles/more-voters-want-democrats-to-control-congressnew-poll-shows-1537707600

Krutka, D. G., \& Carpenter, J. P. (2017). Digital citizenship in the curriculum. Educational Leadership, 75(3), 50-55. 
Levi, L. (2017). Real fake news and fake fake news. First Amendment Law Review 16, 232-327.

Lippmann, W. (1922/2010). Public opinion. Blacksburg, VA: Wilder Publications.

Mason, L. \& Metzger, S. (2012). Reconceptualizing media literacy in the social studies: A pragmatist critique of the NCSS position statement on media literacy. Theory and Research in Social Education, 40(3), 436-455. DOI:

10.1080/00933104.2012.724630

McGrew, S., Breakstone, J., Ortega, T., Smith, M., \& Wineburg, S. (2018). Can students evaluate online sources? Learning from assessments of civic online reasoning. Theory \& Research in Social Education, 46(2), 165-193.

McNair, B. (2018). Fake news: Falsehood, fabrication and fantasy in journalism. New York: Routledge.

Merriam-Webster Dictionary (n. d.) The real story of fake news. Retrieved on July 2, 2018 from: https://www.merriam-webster.com/words-at-play/the-real-story-of-fakenews

Mihailidis, P. (2018). Fake news: Is media literacy a solution? Retrieved on July 12, 2018 from: http://www.wise-qatar.org/fake-news-media-literacy-solution-paulmihailidis

National Association for Media Literacy Education (2007). Core principles of media literacy

education in the United States. Retrieved from https://namle.net/publications/coreprinciples/

Postman, N. (2000). Building a bridge to the eighteenth century: How the past can improve our future. New York: Alfred A. Knopf, Inc.

Shearer, E. and Gottfried, J. (2017). News Use Across Social Media Platforms 2017. Washington D.C.: Pew Research. Retrieved from

http://assets.pewresearch.org/wpcontent/uploads/sites/13/2017/09/13163032/PJ 17.08.23 socialMediaUpdate FINAL.pdf

Stoddard, J. (2014). The need for media education in democratic education. Democracy and Education 22(1), Article 4. Available at: http://democracyeducationjournal.org/home/vol22/iss1/4

Tufekci, Z. (2017). Twitter and tear gas: The power and fragility of networked protest. New Haven, CT: Yale University Press.

Vaidhyanathan, S. (2018). Antisocial media: How Facebook disconnects us and undermines democracy. New York, NY: Oxford University Press. 